\title{
Elaboration of the Method for Safety Assessment of Subsea Pipeline with Longitudinal Buckling
}

\author{
Liudmila Muravyeva and Nikolai Vatin \\ St. Petersburg State Polytechnical University, Saint Petersburg 195251, Russia \\ Correspondence should be addressed to Liudmila Muravyeva; rfludmia@yandex.ru
}

Received 30 November 2015; Accepted 24 April 2016

Academic Editor: Giovanni Garcea

Copyright ( 2016 L. Muravyeva and N. Vatin. This is an open access article distributed under the Creative Commons Attribution License, which permits unrestricted use, distribution, and reproduction in any medium, provided the original work is properly cited.

The issue of ensuring longitudinal stability of marine gas pipelines has been raised in view of construction of pipelines operating at significant temperature drops. Most commonly the pipelines deviation from the design conditions as well as equilibrium disturbance occurs due to longitudinal buckling. The task of designing the marine gas pipeline involves making the reliability analysis of the pipeline, taking into account the required conditions of structural reliability in all construction phases. As per the Russian standards, the vertical buckling is not considered in the stability analysis, whereas the standards of the USA, Norway (DNVRP-F110), and the Great Britain emphasize the need for considering the lateral buckling caused by axial forces. This paper focuses on the operational reliability calculation for an underwater main gas pipeline, in which longitudinal buckling failure occurred. The calculation is based on the probabilistic and statistical method of assessing the pipeline state and operational reliability.

\section{Main Text}

The problem of ensuring longitudinal stability of largediameter underground/subsea pipelines is peculiar to gas pipelines laid in the areas with severe geotechnical conditions. The issue of ensuring longitudinal stability for such structures emerged from the construction of pipelines operating at significant temperature differences. Longitudinal buckling is the most common cause of their operation at off-design conditions and disturbance of their equilibrium.

This paper focuses on the operational reliability analysis of a section of the subsea main gas pipeline, in which longitudinal buckling failure occurred, based on the probabilisticstatistical method for assessing the state of the pipeline and operational reliability of the structure.

In recent years, considerable attention has been given to the fault diagnosis, that is, detecting pipe defects along the route. But the basic question that needs to be answered based on the results of the pipeline route survey in order to make a decision is whether the pipeline section is in serviceable condition if there are faults and defects. Ensuring longitudinal stability of a pipeline structure implies studying the possibility of a nonequilibrium situation occurring to this structure.

Among the first publications on the issue of ensuring longitudinal stability for pipelines are papers by Aleshin et al. [1], Borodavkin and Shadrin [2], Bolotin [3], and Palmer et al. [4]. Having described the pipeline model [5-7] as a flexible beam on rigid foundation subjected to longitudinal force, which changes with increasing deflection and lateral load, the authors used it to calculate the stability of a pipeline under transverse-longitudinal bending.

To solve the problem, the energy criterion of stability was used, which reduces to determining the energy states for the deflected position of the system.

\section{The Problem Was Solved by Ritz Method}

Total energy of the system with pipeline subjected to strains is

$$
T_{E}=U-W,
$$

where $U$ is pipeline strain energy made up of bending strain energy $U_{1}$ plus compressive strain energy $U_{2}$ and $W$ is work of external forces on pipeline displacements. 
The longitudinal stress $\left(\sigma_{l}\right)$ is the axial stress experienced by the pipe wall and consists of stresses due to bending stress $\left(\sigma_{l b}\right)$; Hoop stress $\left(\sigma_{l h}\right)$; thermal stress $\left(\sigma_{l t}\right)$; and end cap force induced stress $\left(\sigma_{l c}\right)$.

The longitudinal stress can be determined using the equation

$$
\sigma_{l}=0,15 \sigma_{l h}+\sigma_{l b} \pm \sigma_{l t}+\sigma_{l c}
$$

$\sigma_{l t}$ should be ensured such that sign conventions are utilized when employing this equation (i.e., tensile stress is positive).

Hoop stress can be determined using equation

$$
\sigma_{h}=\left(p_{i}-p_{e}\right) \frac{D-t}{2 t}
$$

Initial stresses acting in the pipeline decrease on bending, so that compressive force at the ends of the bent section at any point of strain will be equal to

$$
N=P-\frac{\Delta E F}{L_{n}},
$$

where $\Delta$ is increase in pipeline length:

$$
\Delta=l-\int_{0}^{l} \sqrt{1-\left(\frac{d v}{d s}\right)^{2} d s}
$$

The elastic axis of the pipeline under buckling failure is approximated by function

$$
v=A \sin ^{2} \lambda s, \quad\left(\lambda=\frac{\pi}{l}\right),
$$

which satisfies the geometric boundary conditions $v=v^{\prime}=0$ at $s=0, s=l$. For example, see Figure 1 .

Straight-line position of the pipeline employs the minimum of total energy and hence is the stable one:

$$
\text { If } \sigma^{0} \geq \sigma_{B}^{0}
$$

and transition to adjacent equilibrium states, that is, buckling failure, is possible:

$$
\text { If } \sigma^{0}<\sigma_{H}^{0}
$$

and all bent states of the pipeline are unstable and the basic equilibrium state cannot be disturbed.

\section{The Analysis of Possible Pipeline Deformations}

The analysis of possible pipeline deformations described in $[1,6]$ allows presenting them as follows. Buckling failure in the form of a bulge (Figure 2) is described by the equation

$$
y(x)=f_{0} \sin \frac{2 \pi x}{l}
$$

with buckling failure with deformation as shown in Figure 1.

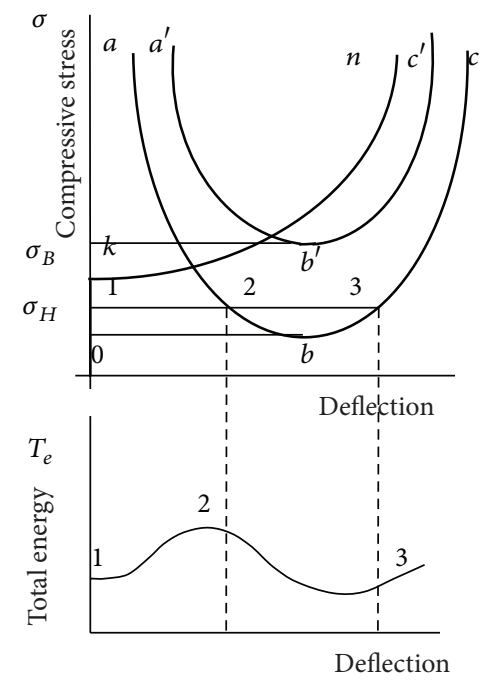

FIGURE 1: Qualitative characteristics of the equilibrium state of the pipeline at the loss of stability.

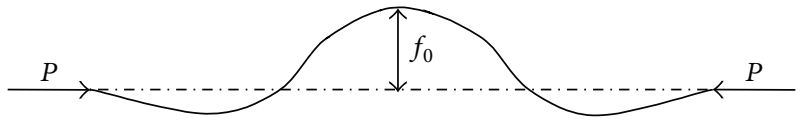

Figure 2: Pipeline buckling form.

Buckling of an underground pipeline in soft soils at the bottom of the trench can occur both in forms shown in Figure 2 and in higher forms as shown in Figure 2.

The deflection forms presented here do not exhaust all possible types of buckling.

However, the occurrence of deflection forms with a great number of nodal points is unlikely $[2,3]$. This is due to the fact that the ultimate environmental resistance is reached only after finite lateral displacements.

\section{The Presentation of an Unburied Pipeline}

In their papers, Aleshin et al. [1,2] suggest the presentation of an unburied pipeline as an infinite rod lying on soil foundation. Foundation reaction per unit of length of the rod was taken, proportionate to displacement, as $R=c v$.

The differential equation of the deflection line was obtained in the following way:

$$
E I \frac{d^{4} v}{d x^{4}}+P \frac{d^{2} v}{d x^{2}}+c v=0
$$

under the following boundary conditions:

$$
\begin{aligned}
v & =0 \\
\frac{d^{2} v}{d x^{2}} & =0 \quad \text { if } x=0, l .
\end{aligned}
$$




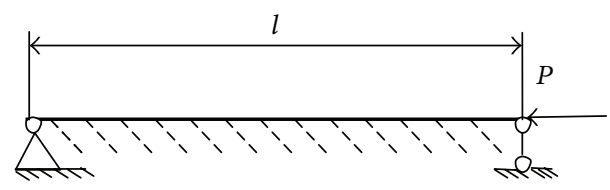

FIGURE 3: Rod lying on elastic foundation.

In (10), $v$ is transverse displacements of the pipeline; $x$ is coordinate along the straight-line axis of the pipeline; and $c$ is foundation resistance.

To find full deflection $v(x)$ of the rod, given the axial force, we obtain the equation, when $N=\alpha E F_{A} \Delta T$ (see Figure 3):

$$
E I \frac{d^{4} v_{1}}{d x^{4}}+N \frac{d^{2} v_{1}}{d x^{2}}+c_{0} v_{1}=r
$$

\section{The Overall Stability of a Pipeline in Longitudinal Direction}

The overall stability of a pipeline in longitudinal direction is checked from the condition

$$
S \leq m N_{\mathrm{cr}}
$$

where $S$ is equivalent longitudinal force in the pipe cross section determined from design loads and effects with account of longitudinal and transverse displacements of the pipeline and $N_{c r}$ is longitudinal critical force at which longitudinal buckling of the pipeline occurs.

Longitudinal stresses in bent sections of underground pipelines are determined in the absence of longitudinal and transverse displacements, subsidence, and soil heaving:

$$
\sigma_{n p \cdot N}=-\alpha E \Delta t+\mu \frac{n p D_{B H}}{2 \delta_{H}} .
$$

It should be noted that operation of main pipelines is characterized by the observed pressure differences caused by pump mode changes.

\section{Numerical Methods}

A comprehensive technology has been developed for assessing the condition of sections of main gas pipelines based on numerical methods used for solving 3D nonlinear problems in continuum mechanics. All calculations of SSS are carried out using the finite element method.

In the first step of calculations, the stress-strain state (SSS) of the pipeline is analyzed in beam approximation and the entire pipeline structure is modeled by straight and curved beams of annular cross section. Structural modeling and analysis at this stage take into account all loads which significantly influence the SSS of the pipeline.

Analysis based on beam model is a way to construct an overall picture of SSS of the pipeline structure, to identify the most loaded sections, and to determine forces and moments at the boundaries of these sections. The calculations are carried out on the assumption of linear-elastic behaviour of the pipe material. Plastic models are considered in the accident analysis.

In the second step, refinement calculations are performed for the most loaded pipeline sections with the use of shell and solid finite element models, Figure 4.

To ensure operational reliability of a gas pipeline, all force and deformation factors affecting it should be assessed. In this regard, among the issues being considered are the serviceability and operational suitability of the pipeline structure, as well as its service time to failure.

\section{Reliability Analysis}

Reliability analysis of the linear pipeline portion is still performed based on conventional methods of structural mechanics using the safety factor concept.

Performance of the linear pipeline section with longitudinal buckling failure was considered and analyzed. Deformations of the buried pipeline structure were studied and analysis of the three-dimensional pipeline structure for deterministic load was presented.

To solve the differential equation of longitudinal and transverse strains for the pipeline of any geometry, the finite element method was used allowing for the representation in matrix form, which is convenient for software.

The solution was obtained by comparing the alternate analytical models, that is, the straight-line section of the pipeline structure and the curved one, in order to better reflect the stress state of the section under consideration.

Given the operating conditions of the pipeline, it is possible to determine three types of accidental impacts: internal pressure for gas pipelines, temperature exposure, and soil pressure (weight).

Solution to this problem is found by statistical modeling of random processes on PC using the deterministic algorithm for determining deformations and internal reactions of the system as described above. Comparison of longitudinal force values in the pipeline cross section is present in Figure 5.

Further, reliability assessment of the damaged pipeline structure in operation was performed using the probabilistic assessment approach to longitudinal and transverse strains, three-dimensional pipeline structure damaged (with buckling arch) from the effect of random weight load from backfill soil as well as random operational loads.

Based on the computed data, the typical combined graph showing the no-failure regions, as presented in Figure 6, was plotted.

System factors are

(i) internal pressure of the transported product $X_{1}=\widetilde{p}$;

(ii) thermal effect of the transported product $X_{2}=\Delta \widetilde{t}$;

(iii) weight effect of backfill soil $X_{3}=\widetilde{q}(x)$.

The prerequisite for serviceability in this problem is that the amount of deflection and stresses in the structure and strength requirements at certain load level are not exceeded. 


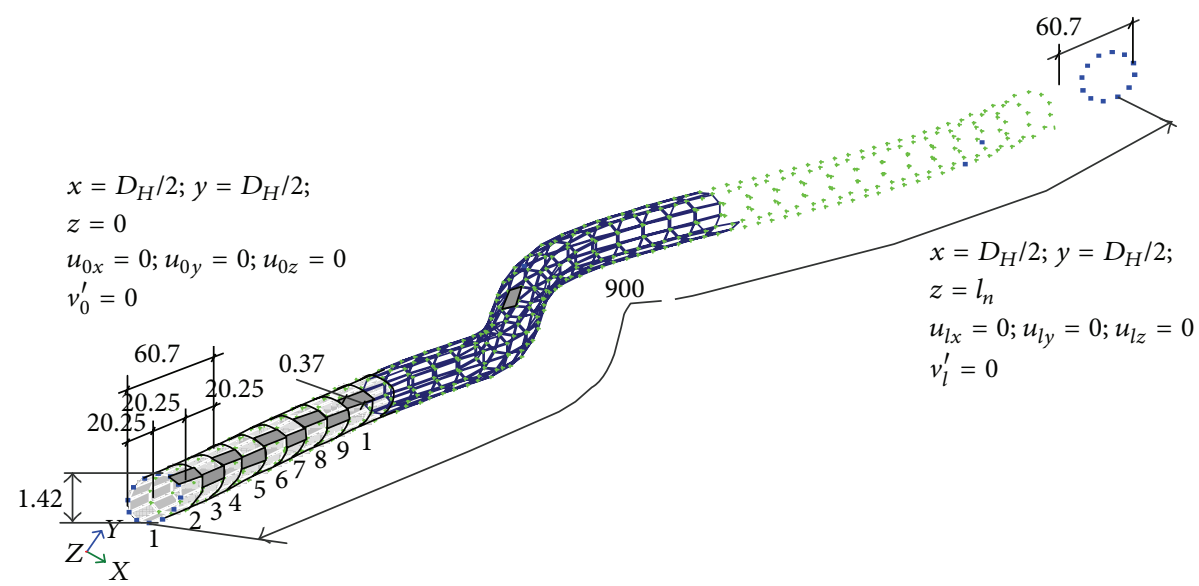

FIGURE 4: Basic arrangement of the pipeline section with rigidly fixed ends.

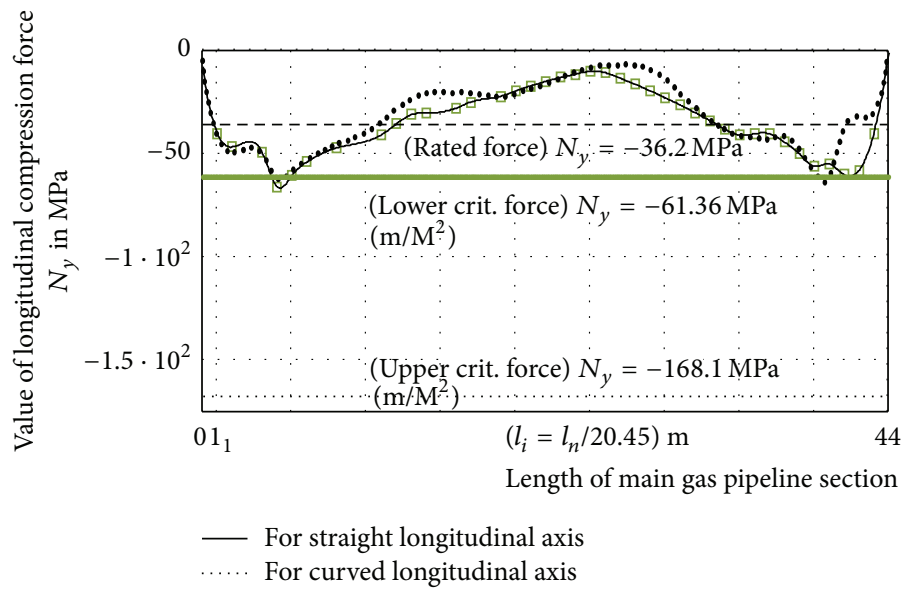

FIGURE 5: Comparison of longitudinal force value in the pipeline cross section.

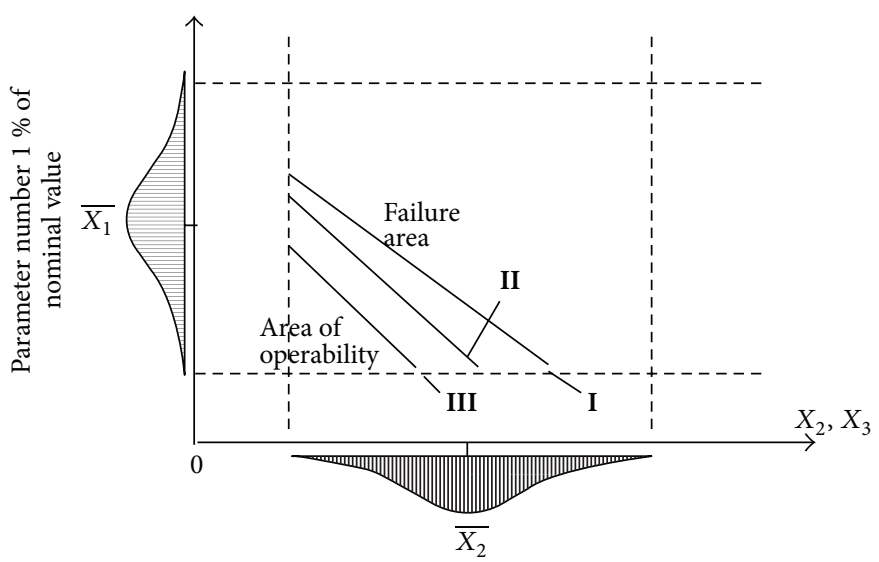

FIGURE 6: Compound diagram of failure-free operation areas.

The next problem to solve is to determine the nofailure region of the linear section of the main gas pipeline by creating the analytical model defining the structural reliability function based on variations in operational load levels. The amount and procedure for computer calculations were determined using the design-of-experiment technique.

The appropriate level of structural reliability is established based on the performance and reliability analysis of the existing structures, Figure 6. 
For probability calculations, the following values can be used as a first approximation:

(i) For probability of three standard deviations, $P(F<$ $R)=0,998(\mathbf{I})$.

(ii) For probability of two standard deviations, $P(F<$ $R)=0,956$ (II).

(iii) For probability of one standard deviation, $P(F<R)=$ 0,683 (III).

\section{Nomenclature}

E: Elasticity modulus of pipeline material

I: $\quad$ Moment of inertia of the metal cross section

$P$ : Compressive force acting on the pipeline until buckling

$\delta_{H}$ : Pipe wall thickness

$D$ : Pipe outer diameter

$\mu$ : Poisson's ratio

$\alpha$ : Coefficient of linear expansion

$S$ : Equivalent longitudinal force in the pipe cross section

$N_{\text {cr: }}$ Longitudinal critical force

$m$ : Service factor of the pipeline.

\section{Competing Interests}

The authors declare that they have no competing interests.

\section{References}

[1] V. V. Aleshin, V. E. Seleznev, G. S. Klishin, V. V. Kobyakov, and K. I. Dikarev, Chislennyj Analiz Prochnosti Podzemnyh Truboprovodov, Editorial URSS, Moscow, Russia, 2003.

[2] P. P. Borodavkin and O. B. Shadrin, Podvodnye Truboprovody, Nedra, Moscow, Russia, 1979 (Russian).

[3] V. V. Bolotin, "Ob uprugikh deformatsiyakh podzemnykh truboprovodov, prokladyvayemykh statisticheski neodnorodnom grunte," Stroitelnaya Mekhanika i Raschet Sooruzheni, no. 1, p. 52, 1965 (Russian).

[4] A. C. Palmer, C. P. Ellinas, D. M. Richards, and J. Guijt, "Design of submarine pipelines against upheaval buckling," in Proceedings of the 22nd Offshore Technology Conference, Houston, Tex, USA, 1990.

[5] L. V. Muravieva, I. G. Ovtchinnikov, and V. A. Pshenichkina, Estimation of reliability a pipeline construction with operational damage, Saratov, Russia, 2004.

[6] L. V. Muravyeva and N. I. Vatin, "The safety estimation of the marine pipeline," Applied Mechanics and Materials, vol. 633634, pp. 958-964, 2014.

[7] L. V. Muravyeva and N. I. Vatin, "Study of integrity and interaction of a non-buried marine subsea pipeline with soil," Applied Mechanics and Materials, vol. 633-634, pp. 1042-1046, 2014. 


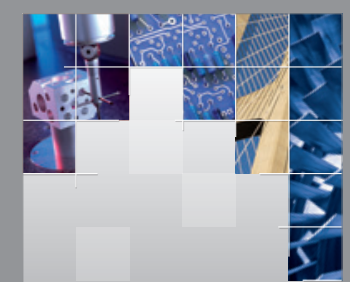

\section{Enfincering}
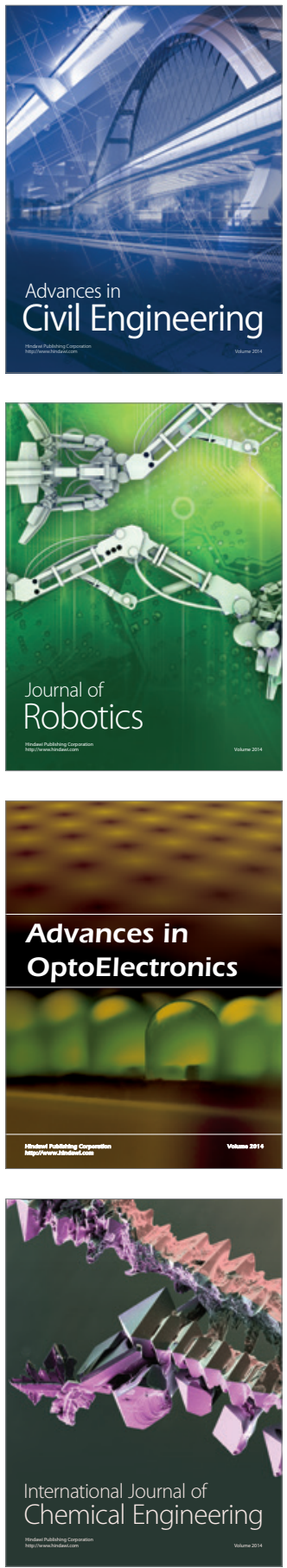

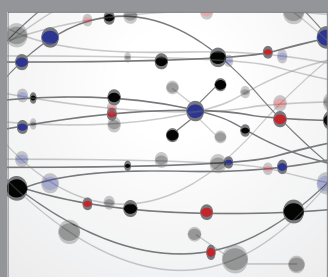

The Scientific World Journal

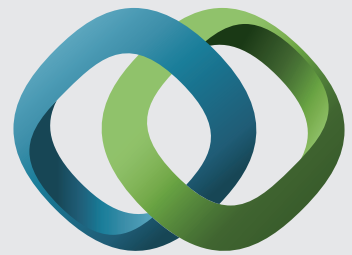

\section{Hindawi}

Submit your manuscripts at

http://www.hindawi.com
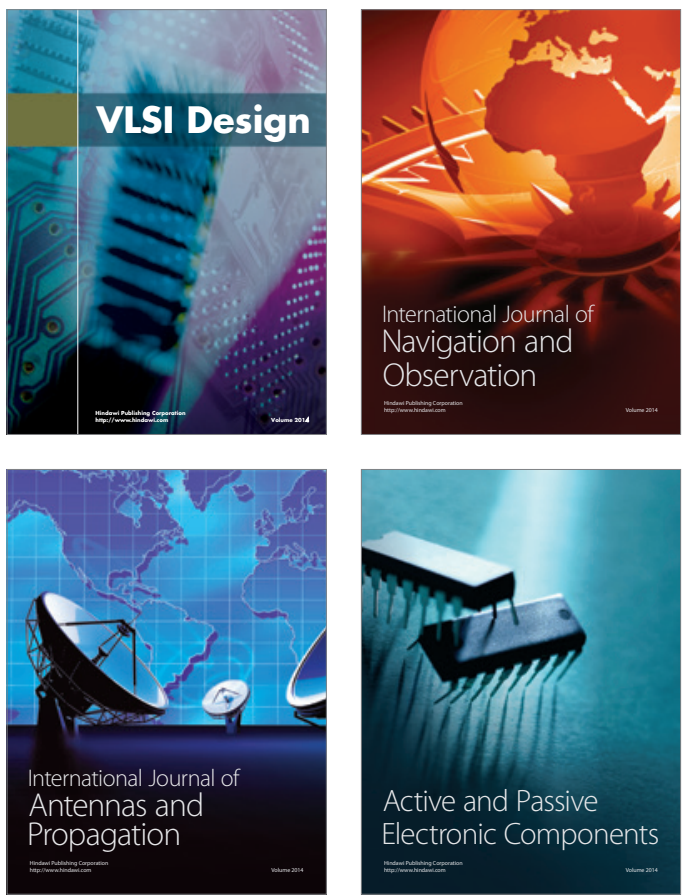
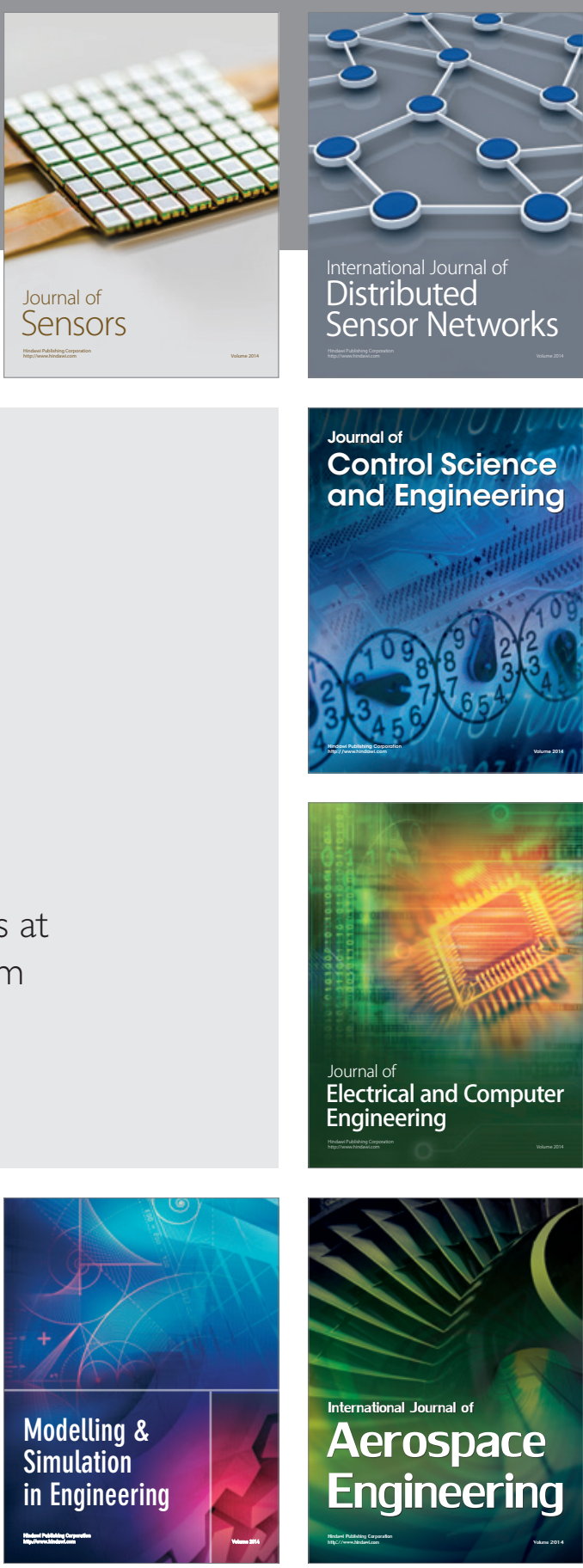

International Journal of

Distributed

Sensor Networks

Journal of

Control Science

and Engineering
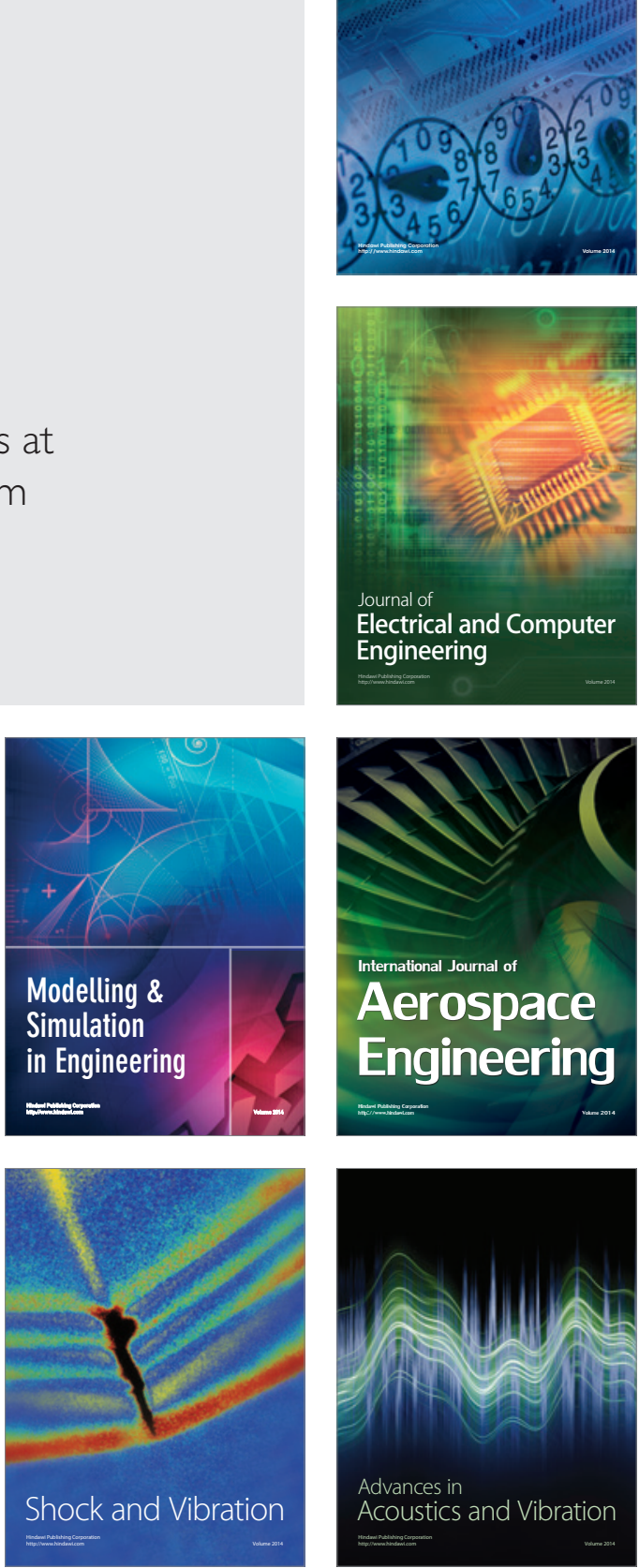